\title{
Correction to: The impact on renal function after longterm use of anticoagulants in atrial fibrillation patients
}

Wei-Chieh Lee ${ }^{1,2}$, Pai-Wei Lee ${ }^{3}$, Po-Jui Wu ${ }^{2}$, Yen-Nan Fang ${ }^{2}$, Huang-Chung Chen ${ }^{2}$, Yu-Sheng Lin ${ }^{4}$, Hsiu-Yu Fang ${ }^{2}$, Shang-Hung Chang ${ }^{3}$, Ping-Yen Liu ${ }^{1 *}$ and Mien-Cheng Chen ${ }^{2^{*}}$

\section{Correction to: Thrombosis J 19, 98 (2021) https://doi.org/10.1186/s12959-021-00351-1}

Following publication of the original article [1], an error was reported in the authorship list. Wei-Chieh Lee was reported as the corresponding author, however Ping-Yen Liu and Mien-Cheng Chen are the correct co-corresponding authors as shown in this Correction article.

The original article [1] has been corrected.

\section{Author details}

${ }^{1}$ Institute of Clinical Medicine, College of Medicine, National Cheng Kung University, Tainan, Taiwan. ${ }^{2}$ Division of Cardiology, Department of Internal Medicine, Kaohsiung Chang Gung Memorial Hospital, Chang Gung University College of Medicine, 123 Ta Pei Road, Niao Sung District, Kaohsiung City 83301, Taiwan. ${ }^{3}$ Center for Big Data Analytics and Statistics, Chang-Gung University and Hospital, Taipei, Taiwan. ${ }^{4}$ Division of Cardiology, Chang Gung Memorial Hospital, Chiayi, Taiwan.

Published online: 30 December 2021

\section{Reference}

1. Lee WC, Lee PW, Wu PJ, Fang YN, Chen HC, Lin YS, et al. The impact on renal function after long-term use of anticoagulants in atrial fibrillation patients. Thrombosis J. 2021;19:98. https://doi.org/10.1186/s12959-021-00351-1.

\footnotetext{
The original article can be found online at https:/doi.org/10.1186/s12959021-00351-1.

*Correspondence: larry@mail.ncku.edu.tw; chenmien@ms76.hinet.net 'Institute of Clinical Medicine, College of Medicine, National Cheng Kung University, Tainan, Taiwan

${ }^{2}$ Division of Cardiology, Department of Internal Medicine, Kaohsiung Chang Gung Memorial Hospital, Chang Gung University College of Medicine, 123 Ta Pei Road, Niao Sung District, Kaohsiung City 83301, Taiwan

Full list of author information is available at the end of the article
}

(c) The Author(s). 2021 Open Access This article is licensed under a Creative Commons Attribution 4.0 International License, which permits use, sharing, adaptation, distribution and reproduction in any medium or format, as long as you give appropriate credit to the original author(s) and the source, provide a link to the Creative Commons licence, and indicate if changes were made. The images or other third party material in this article are included in the article's Creative Commons licence, unless indicated otherwise in a credit line to the material. If material is not included in the article's Creative Commons licence and your intended use is not permitted by statutory regulation or exceeds the permitted use, you will need to obtain permission directly from the copyright holder. To view a copy of this licence, visit http://creativecommons.org/licenses/by/4.0/ The Creative Commons Public Domain Dedication waiver (http://creativecommons.org/publicdomain/zero/1.0/) applies to the data made available in this article, unless otherwise stated in a credit line to the data. 